\title{
Erratum to: A morphological and life history comparison between desert populations of a sit-and-pursue antlion, in reference to a co-occurring pit-building antlion
}

\author{
Inon Scharf • Ido Filin • Aziz Subach • Ofer Ovadia
}

Published online: 7 March 2010

(C) Springer-Verlag 2010

Erratum to: Naturwissenschaften

DOI 10.1007/s00114-009-0576-z

Unfortunately, there are two typing errors, which require correction:

(1) Equation 2 in page 1151 should be: $\mathrm{CV}=0.0587^{*}$ $\mathrm{DBM}+0.1131 * \mathrm{ML}+0.3527 * \mathrm{CML}-0.1407 * \mathrm{MW}-$ $0.0386 * \mathrm{HL}+0.7319 * \mathrm{HW}+0.0351 * \mathrm{~T} 13+0.0626 *$ $\mathrm{T} 23+0.1434 * \mathrm{TL}-0.0335 * \mathrm{TW}+0.1113 * \mathrm{AL}+0.1393 *$ AW

(2) In page 1151, Table 2, the last value in the column representing the PC loadings for the first PC of $L$. fedtschenkoi (LfPC1) should be 0.5057 instead of 0.8843 .

The online version of the original article can be found under http://dx. doi.org/10.1007/s00114-009-0576-z.

I. Scharf $(\bowtie) \cdot$ A. Subach $\cdot$ O. Ovadia

Department of Life Sciences,

Ben-Gurion University of the Negev,

P.O. Box 653, Beer-Sheva 84105, Israel

e-mail: schari@bgu.ac.il

I. Filin

Department of Mathematics and Statistics, University of Helsinki,

P.O. Box PL 68, 00014 Helsinki, Finland 